\title{
Comparison of Chemical Compounds of Essential Oils from Natural Agarwood and Inoculated Agarwood (Roselle-Based Inoculation)
}

\author{
N.R.M., Nasardin ${ }^{1}$, M.A.M., Hanafiah ${ }^{2}$, M., Zainon ${ }^{3}$, M., Ibrahim ${ }^{4}$, A.I.A., Rahman5, \\ Z.A. Baharudin ${ }^{6}$, M.H.M., Husin ${ }^{7}$, I. Mahir ${ }^{8}$, A.A., Zulkefle ${ }^{9}$ \\ ${ }^{1,9}$ Faculty of Electrical Engineering, Universiti Teknikal Malaysia Melaka, Hang Tuah Jaya, 76100 Durian Tunggal, \\ Melaka, Malaysia \\ ${ }^{2,3,4,5,6}$ Faculty of Engineering Technology, Kampus Teknologi, Universiti Teknikal Malaysia Melaka, Hang Tuah Jaya, \\ 76100 Durian Tunggal, Melaka, Malaysia \\ ${ }^{7}$ Faculty of Mechanical Engineering, Kampus Teknologi, Universiti Teknikal Malaysia Melaka, Hang Tuah Jaya, 76100 \\ Durian Tunggal, Melaka, Malaysia \\ ${ }^{8}$ Mahir Enterprise Gaharu, No. EF 536, Kampung Ketapang Hilir, 26600 Pekan, Pahang, Malaysia
}

\begin{tabular}{l} 
Article Info \\
\hline Article history: \\
Received Feb 1, 2018 \\
Revised Apr 20, 2018 \\
Accepted Apr 27, 2018 \\
\hline
\end{tabular}

Keywords:

Agarwood Oil

Steam Distillation

Hydro-distillation

\begin{abstract}
In this paper, the physical and structural properties of the natural agarwood and inoculated agarwood using Roselle-based inoculation had been discussed. The results showed that a high volume of oil obtained on day 1 by the inoculated agarwood which yielded $3 \mathrm{ml}$ of the agarwood oil as compared to the natural agarwood that had yielded only $2.3 \mathrm{ml}$. In the chemical analysis, five major compounds were detected by FTIR which were C-O bond (aromatic alkane), C-C stretching (aromatic alkane), C-O stretching (ether) and $\mathrm{C}-\mathrm{H}$ bond (aromatic ring) in both oils. Moreover, the inoculated agarwood exhibited better oil production compared to the natural agarwood.
\end{abstract}

Copyright (c) 2018 Institute of Advanced Engineering and Science. All rights reserved.

\section{Corresponding Author:}

N.R.M., Nasardin,

Faculty of Electrical Engineering, Universiti Teknikal Malaysia Melaka,

Hang Tuah Jaya, 76100 Durian Tunggal, Melaka, Malaysia.

Email: ariff@utem.edu.my

\section{INTRODUCTION}

In Malaysia today, Agarwood is a highly valuable wood also known as "Black Gold". Agarwood is found in Aquilaria species of the Thymelaeaceae family. There are three species found in South East Asia; Aquilaria Crassna, Aquilaria Subintegra and Aquilaria Malaccensis [1]. Agarwood has a variety of names depending on the places and local cultures where it is found.The word "Gaharu" is in Malay, while the word "Agar" is in Hindi, and it is originated from the Sanskrit word "Aguru", which is also directly used in Bengali, Telugu and Kannada[3]. As for the Vietnamese, Agarwood is known as Trầmhurong, Chénxiāng in China, while the word Jinkō in Japanese means the "sinking incense”. In Japan, there are various grades of Jinkō, and the highest grade of Jinkō is known as Kyara [4].

Black Gold is a dark resinous heartwood. Heartwood can be infected several ways such as using mold in an inoculation process, via lightning treatment or left to nature to perform its work. When the wood is infected, the tree will produce a dark, dense, aromatic resin which is commonly known as agarwood's core [2]. A formation of agarwood occurs in the trunk and roots of trees that have been infected by parasites. In response, the tree produces a resin high in volatile-organic compounds that aids in suppressing or retarding the infection, and this process is called tylosis. While the tree's unaffected wood is relatively light in colour, 
the resin dramatically increases the mass and density of the affected wood, thus changing its colour from a pale beige to a dark brown or black [5].At present, the price for a super grade Agarwood core is more than RM12,000 for one Kilogram (Kg).

In this paper, the differences between the natural wood and inoculated wood of agarwood with the same process will be discussed. Some attributes will be analysed based on the chemical compound of the oil production by using FTIR.

\section{METHODOLOGY}

Agarwood tree needs to be wounded to stop the flow of its sap (rubber) inside the tree and gather it in one place. After the accumulation of sap inside the agarwood tree is completed, it will be used to produce the agarwood oil. Almost $70 \%$ of the wood oil will be produced from the accumulated sap. Each type of agarwood tree has different percentage of oil content. Many Agarwood manufacturers in Malaysia process the oil by using the wood from Subintegra and Malaccensis species. In Thailand, the plantation involved in the agarwood project has created a unique process in which the agarwood resin can be produced inside every Aquilaria tree on their plantation [5] as according to Figure 1.

There are two methods to wound the tree which is either with a natural method or a compulsory method. Often the natural method requires the tree to grow up until the tree is old enough. When the tree is old, its antibody becomes weak, therefore the sap inside the tree will naturally stop flowing and form a resin. Another method is the effect from lightning strike. This effect also can wound the tree and produce heat inside the tree. Most of the time, the lightning effect method will produce almost $40 \%$ to $50 \%$ of wood oil. There are some researches that have succesfully produced valuable wood oil from the lightning treatment by placing a rod of the positive ions inside the wood.
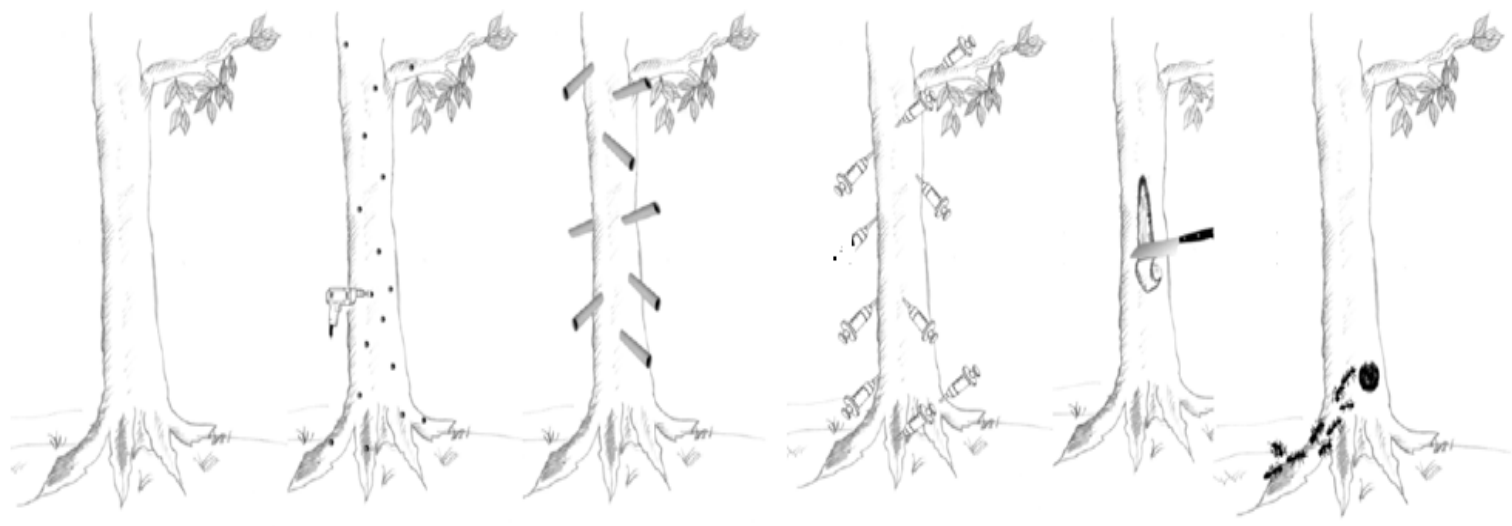

Figure 1. The unique technique for inoculation in Thailand [5]

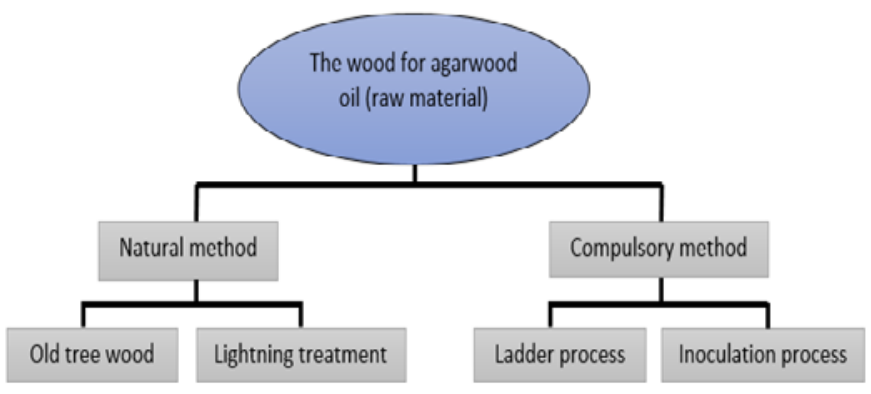

Figure 2. The classification of agarwood method to make the oil wood

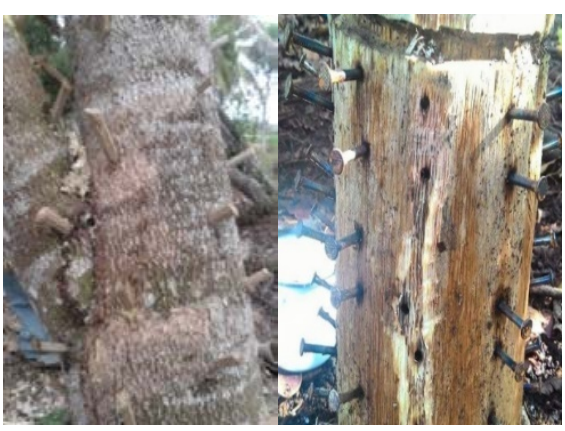

Figure 3. The ladder process for compulsory method 
There are two types of processes in the compulsory method, the first process is known as the ladder process and the second is the inoculation process. The ladder process is used by indigenous people in the forest. They use either twigs or nails as according to Figure 3. The nailing process is done around the tree trunk until it becomes a ladder system. Typically, this process is applied to old trees, aged approximatedly 20 to 50 years old. Another process of producing agarwood oil through the compulsary method is the inoculation process. The process of inoculation method is by inserting a chemical liquid into the agarwood tree and it is shown in Figure 4. The chemical liquid is used to produce bacterial or fungi infection that will wound the tree. There are many agarwood producers who use illegal chemical substances by mixing toxic substances. When this toxic liquid is used to wound the wood, it will affect the oil produced and may cause human skin to itch upon contact with it. The content of the chemicals used should also depend on the tree size and its antibody level. Usually, a 2 year old tree can undergo the inoculation process using a 2 to 3 inches of tree coil. The Roselle-based inoculation uses chemicals from natural ingredients such as mineral water, sugar palm, bamboo shoots, black glutinous rice, the wood of agarwood and the main ingredient is the roselle fruit. All of these ingredients will be cooked and fermented for about 2 weeks until gas is released and fungi appear. This process is similar to the process of producing alcoholic drink such as wine that uses grapes. The fermentation process in the wine-making produces alcohol, whereas Roselle-based Inoculation did not produce any alcohol. Figure 5 shows the effectiveness of chemicals from Roselle-based Inoculation to produce oil for the agarwood. Almost 55\% of the production is the wood oil whereas another $30 \%$ is the core of the agarwood.

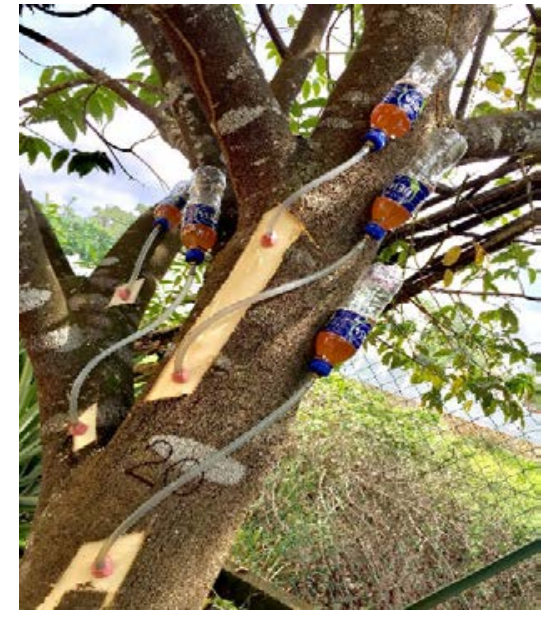

Figure 4. The Inoculation process with Rosellebased Inoculation

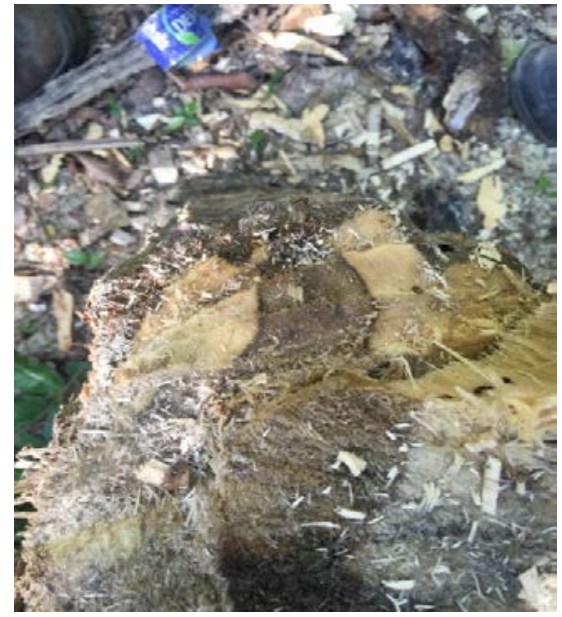

Figure 5. The effect after 6 months of inoculation from Roselle-based Inoculation of a 20-years-old tree

\section{RESULT AND DISCUSSION}

Two types of agarwood chips were used to investigate the effects of oil yield. The effect of natural agarwood and inoculated agarwood on oil yield is depicted in Figure 5. The summary of functional group for both samples of pure agarwood wood and inoculation agarwood wood is given.The duration for both processes is the same which is 5 days. The results exhibit the inoculated agarwood chip produces a higher volume of oil, over 4-5 ml, compared to the natural agarwood. This finding is supported by Rozi Mohamed et al [6] and Chang et al [7] that inoculated agarwood could accelerate the production of agarwood oil by promoting resin formation.

An analysis by Fourier Transform Infrared Spectroscopy (FTIR) proved the produced agarwood oil is of high quality. FTIR is used to obtain an infrared spectrum of absorption of the agarwood oil. Simultaneously, it can collect data quickly and accurately with a high-spectral-resolution data over a wide spectral range. This spectrum was recorded at the range of 4000 to $400 \mathrm{~cm}^{-1}$ (mid infrared spectroscopy) at $4 \mathrm{~cm}^{-1}$ resolution (FTIR model: Perkin Elmer 2000).

According to the results in Figure 7 and Table 1, the entire chemical compound for agarwood oil inside the oil was found. The presence of $\mathrm{C}-\mathrm{O}$ bond (aromatic alkane), C-C stretching (aromatic alkane), C-O stretching (ether) and $\mathrm{C}-\mathrm{H}$ bond (aromatic ring) in both oils explains the phenomenon of sweet and pleasant smell detected during the extraction process. Based on the generated wavenumber in Table 1 bands, both of the oils show that the H-O-H (water) is verified to be absent in this chemical compounds. Both samples did 
not show the presence of any alcohol functional group (O-H bond); it isconfirmed that this agarwood oil is naturally pure and in high quality. Other than that, it proves that the Roselle-based Inoculation process did not contain any achohol and the liquid is in a form of natural liquid.

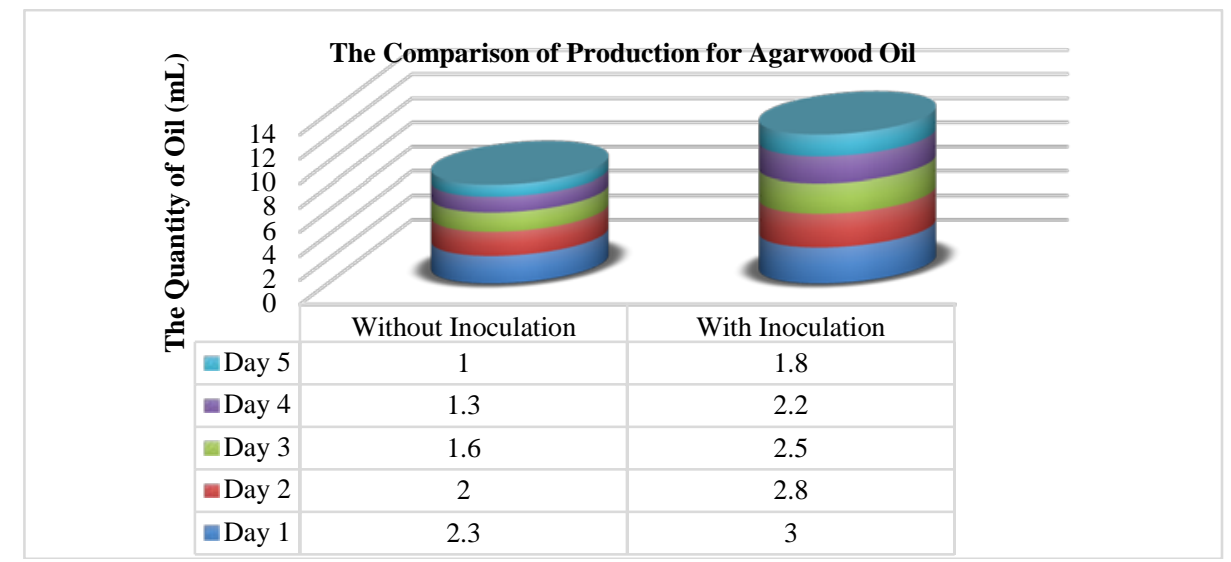

Figure 6. The comparison of production for Agarwood Oil
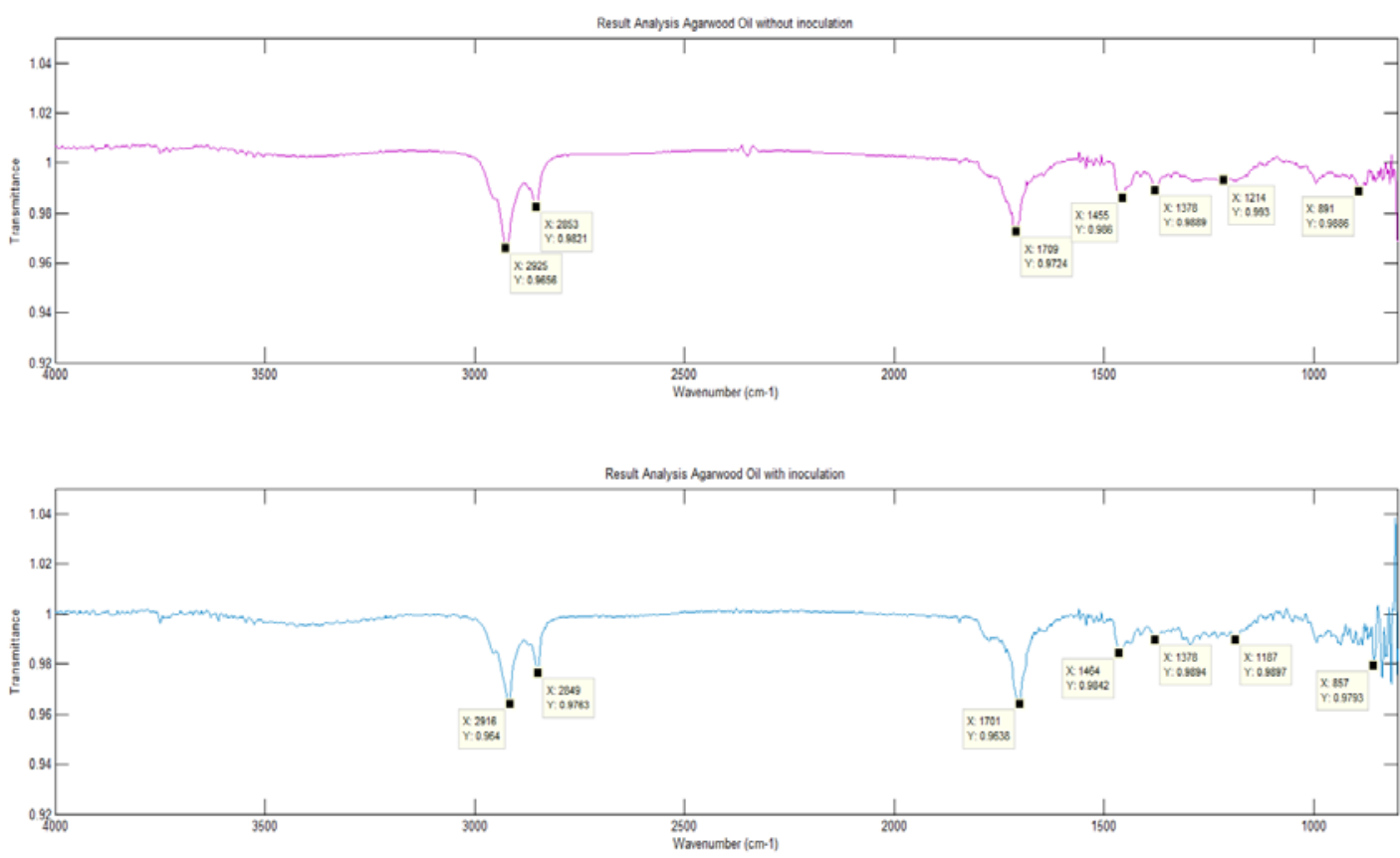

Figure 7. The Result analysis for Agarwood Oil

Table 1. The Result analysis for Agarwood Oil [8], [9]

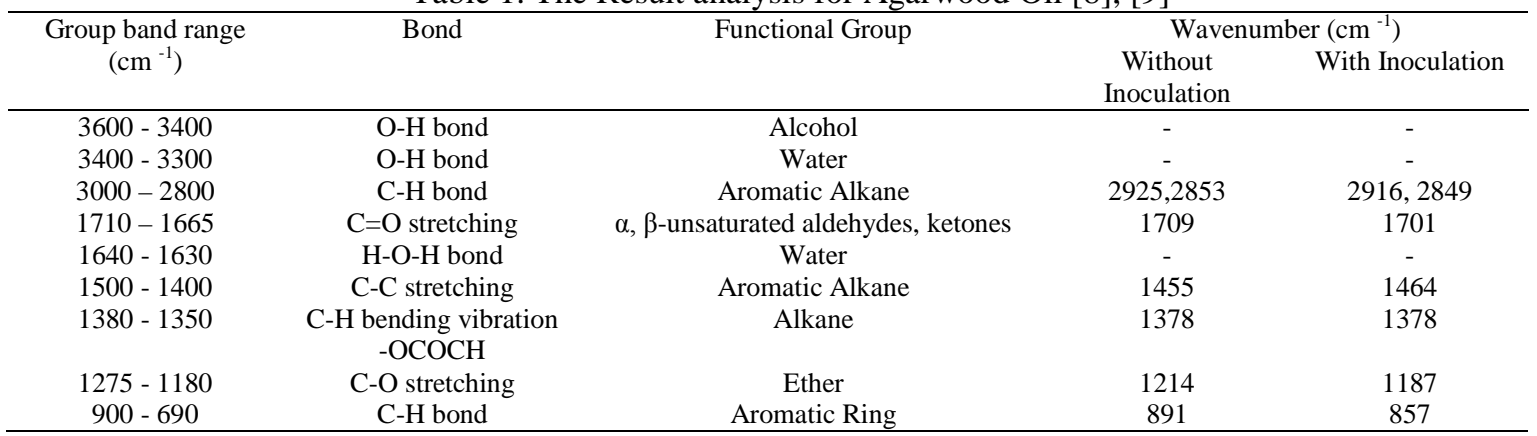




\section{CONCLUSION}

As a conclusion, the inoculated agarwood chip produces a higher volume of oil compared to the natural agarwood chip. The optimum parameter of the inoculated agarwood is obtained from the highest oil yield, identified in day 1 which it yield $3 \mathrm{ml}$ of agarwood oil compared to other days. The combination of Agarwood and Roselle-based inoculation exhibits better oil yield compared to the natural agarwood. In the chemical analysis, five major chemical compounds were found in all extracted oils, namely C-O bond (aromatic alkane), C-C stretching (aromatic alkane), C-O stretching (ether) and C-H bond (aromatic ring).

\section{ACKNOWLEDGEMENTS}

The authors would like to thank Universiti Teknikal Malaysia Melaka (UTeM; Grant Ref. No. PJP/2015/FTK(4C)/S01404 and PJP/2017/FTK-AMC/S01575), Ministry of Science, Technology and Innovation (MOSTI), Ministry of Higher Education (MoHE), and the Government of Malaysia for the support and assistance rendered to this research.

\section{REFERENCES}

[1] Pornpunyapat, J., Chetpattananondh, P., \& Tongurai, "Mathematical modeling for extraction of essential oil from Aquilaria Crassna by hydrodistillation and quality of agarwood oil,”Bangladesh Journal of Pharmacology., 2011, 6(1), 18-24.

[2] Blanchette, R.A., "Cultivated Agarwood-Training programs and Research in Papua New Guinea", Forest Pathology and Wood Microbiology Research Laboratory, Department of Plant Pathology, University of Minnesota,2006.

[3] Bouverie, P.E. "Daniel the Prophet: Nine Lectures", Delivered in the Divinity School of the University of Oxford, Funk \& Wagnalls, New York, 1885, p. 515.

[4] Morita, K., The Book of Incense: Enjoying the Traditional Art of Japanese Scents,2007.

[5] Selina Akter, Md. Tanvir Islam, Mohd Zulkefeli, S. I. K., "Agarwood Production- A Multidisciplinary Field To Be Explored In Bangladesh,” International Journal of Pharmaceutical and Life Sciences, 2013,2(1), $22-32$.

[6] Rozi Mohamed, The Book of Incense: Agarwood Science Behind the Fragrance,2007.

[7] Selina Akter, Md. Tanvir Islam, Mohd Zulkefeli, S. I. K., "Agarwood Production- A Multidisciplinary Field To Be Explored In Bangladesh,” International Journal of Pharmaceutical and Life Sciences, 2013,2(1), $22-32$.

[8] Syaima M.T.S., Adam F., Nizam A.S.M, Farah M.Z.Y. and Saufi S.M.S., "Molecular Nano-Sieve Approach by the application of Polypiperazine (PPA) Based Membrane for the Recovery of Water Soluble Agarwood (Aquilaria Malaccensis) Marker Molecules,” ARPN Journal of Engineering and Applied Sciences, Vol. 11, No.4, pp.2174-2178, February 2016.

[9] Nur Farhana J., Miradatul N.M.R., Nur Hidayah Z., Nursyuhada C.H. and Ahmad Fakhri S.M., "FTIR Analysis of Phenolic Compound as Pancreatic Lipase Inhibitor from Inoculated Aquilaria Malaccensis,” The Malaysian Journal of Analytical Sciences, Vol.18, No.3, pp.683-689, 2014 